\title{
TRAIL FOLLOWING AND ITS DEVELOPMENT IN THE NEOTROPICAL ARMY ANT GENUS ECITON (HYMENOPTERA: FORMICIDAE: DORYLINAE)
}

\author{
By Howard Topoff, Katherine Lawson \\ and Patricia Richards ${ }^{1}$
}

\section{INTRODUCTION}

Results of numerous field studies on the neotropical army ants Eciton hamatum (Fabricius) and E. burchelli (Westwood) have shown that newly eclosed callow workers do not participate in adult activities such as raiding until they have matured in the colony environment for several days after the onset of the nomadic phase. Nevertheless, the callows of both species do emigrate along with the colony, beginning on the very first nomadic day (Schneirla, I97I). We have offered several hypotheses to account for the behavioral deficit of the callows. One hypothesis proposes that the sensitivity of the callows to their colony's chemical trail is too low for them to be able to follow along it during the day's raid. By late afternoon, however, the strength of the trail may be sufficiently increased (as it is constantly reinforced by tens of thousands of ants running back and forth over it) so that the callows are able to participate in the emigration. This paper presents the results of a study designed to compare the performance of callow and mature adult workers of E. hamatum and E. burchelli on their own colony's trail.

\section{Methods}

This study was conducted on Barro Colorado Island, Panama Canal Zone. Features of the Island that make it suitable for army ant research have been described by Rettenmeyer ( 1963 ).

Field methods consisted of daily patrols of the Island's numerous trails to locate statary colonies. The first indication that a colony was about to enter a new nomadic phase was the appearance of empty pupal cases on the ground near the bivouac, and the presence of lightly-pigmented callow workers inside of the nest. The first nomadic day was defined as the day on which the first emigration of the entire colony took place.

Callow and mature adult ants were collected by collapsing a sec-

\footnotetext{
${ }^{1}$ Department of Psychology, Hunter College of the City University of New York, and Department of Animal Behavior, The American Museum of Natural History, New York, N.Y. 10024.

Manuscript received by the editor November 20, 1972
} 
tion of the bivouac wall with a trowel, and allowing the ants to drop into a plastic box. When this method did not yield enough ants, we aspirated additional individuals from the area around the nest. In the laboratory the ants were kept in a glass aquarium.

At the start of each day's test, a petroleum ether extract of whole ants was prepared by adding $60 \mathrm{ml}$ of ether to a jar containing 300 intermediate-sized mature adult ants. A circular trail of the ether extract $(63 \mathrm{~cm}$ in circumference) was deposited on discs of filter paper, by allowing the extract to flow out of a microburet suspended above a phonograph turntable which was spinning at $78 \mathrm{rpm}$. The ether evaporated in 5 seconds, and in order to observe whether the test ants were following the trail, the filter paper was placed upon a corresponding circular template. The template circle, as well as the lines dividing it into 16 sectors, were clearly visible through the discs of filter paper. A new disc of filter paper was used for each trial.

In order to insure uniform orientation of each test ant at the start of trail following, a plastic enclosure was used (Fig. I). It

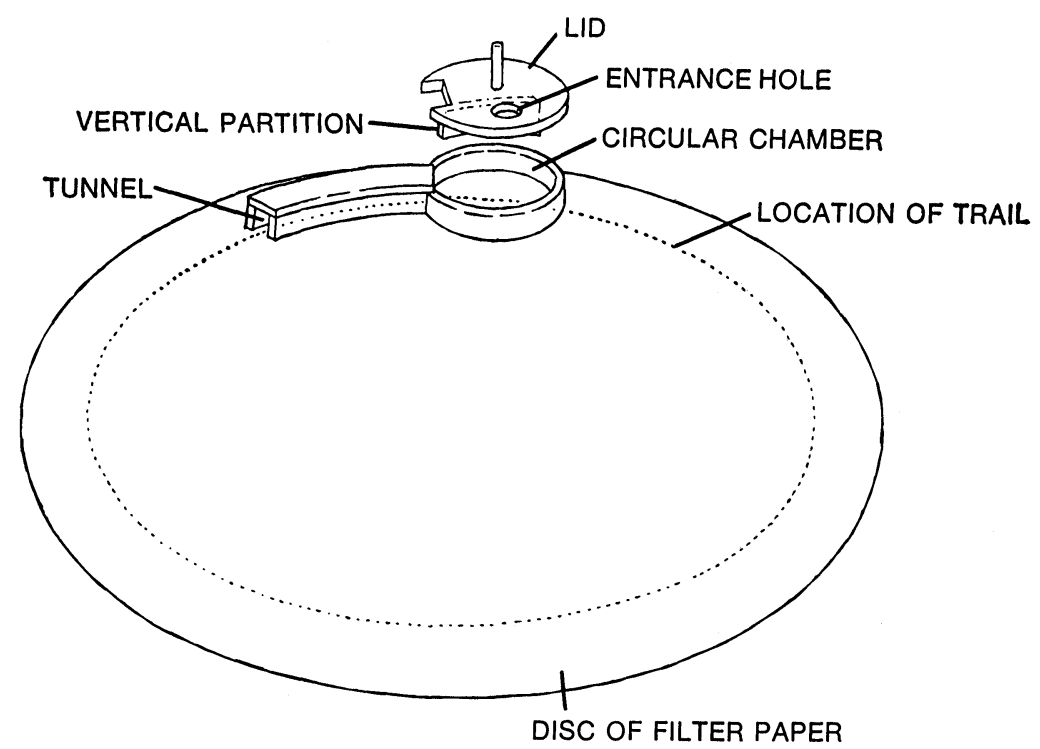

Fig. 1. Apparatus used to insure that all test ants initially orient to the trail in an identical manner. For explanation, see text. 
consisted of a circular chamber $(5.0 \mathrm{~cm}$ in diameter, $1.4 \mathrm{~cm}$ high) which opened into a tunnel that was $7.9 \mathrm{~cm}$ long. The tunnel was the same height as the adjoining circular chamber, and was $1.2 \mathrm{~cm}$ wide. This width was chosen because it was approximately equal to the leg span of the intermediate-sized workers of E. hamatum and $E$. burchelli (i.e., workers whose overall length was between 7.0 and $9.0 \mathrm{~mm}$ ). The curvature of the tunnel was equal to that of the trail.

The circular chamber was divided approximately in half by a vertical partition attached to its lid. Each test ant entered the chamber through a hole in the lid, and the partition prevented it from contacting the trail during the 15 second period in which it was allowed to adapt to the chamber. At the end of this interval the lid with the partition was replaced with another lid without a partition, thus allowing the ant access to the trail.

For each dilution of ether extract that was used, 60 intermediatesized ants ( 30 callows and 30 mature adults) were selected at random from the mass of ants in the aquarium. The dilutions were prepared by adding different amounts of pure ether to the extract. Ants were tested individually, and as indices of trail following we recorded the number of ants following, the distance travelled on the trail (maximum distance $=580 \mathrm{~mm}$ ), and the speed of travel along the trail. If an ant did not leave the runway at the end of one minute, a negative response was recorded.

\section{Results}

The results of comparing trail-following performances between callow and mature adult worker ants from three colonies of $E$. hamatum and one colony of $E$. burchelli are shown in Table $\mathrm{r}$. It is clear that when comparisons are made as to the relative ability of callow and mature adult ants to follow any portion of the trail, as well as comparisons of the number from both groups able to complete the trail, the differences are not significant in approximately two-thirds of the cases. The third measure of trail following we considered was the median distance (in $\mathrm{mm}$ ) followed by callow and mature adult ants in each test series. Again, these differences were usually not significant. The only measure of trail-following performance that consistently illustrated the behavioral immaturity of the callows was their speed of running over the trail. At all dilutions on all nomadic and statary days in which tests were conducted, the running speed of the callows of both species was slower than that of the mature adult ants. 


\section{Discussion}

It is clear that the absence of callow army ants from raiding trails during the first few days of the nomadic phase can not be explained on the basis of their inability to follow the chemical trail of their colony. Nevertheless, there are significant differences in trailfollowing performance between callow and mature adult ants, especially in their speed of running along the trail. If the callows did attempt to participate in raiding activities, their deficit in locomotory ability could make them very inefficient predators. This, together with the observation that callow army ants placed in raiding columns are behaviorally disorganized (Schneirla, I97I) makes it likely that it is adaptive to the colony for the callows not to participate in raiding until they have matured. However, the fact that the behavior of the callows is adaptive to the colony still does not explain the mechanism that keeps them inside of the nest.

Although there is relatively little data on the behavior of the callow workers in the nest immediately after their eclosion, Schneirla (1952) reported that they feed voraciously. Rettenmeyer (I963) also observed callows feeding on booty, but pointed out the difficulty of estimating the quantity of food consumed or the duration of the active feeding periods. If the callows are preoccupied in feeding intensively during the first few days after their emergence from the pupal stage of development, this could account for their absence from raiding columns.

Another hypothesis stems from the observation that callow workers tend to cluster tightly together, both in the bivouac and in emigration columns (Rettenmeyer, 1963; Schneirla, 1938). This intense clustering may result from an extreme sensitivity of the callows to chemical and tactual stimuli. Inside the bivouac the intensity of tactual stimulation is high, as a result of the continual contact among callows and other ants. The nest is also saturated with trail substance and other chemical stimuli (which arise from the workers, the queen, and even the booty). Accordingly, whenever a callow leaves the bivouac the intensity of stimuli impinging upon it decreases abruptly. Outside the nest the amount of tactual stimulation is decreased as the adult ants fan out along the trail. The intensity of chemical stimuli is also decreased, as volatile chemicals diffuse and as the concentration of trail chemicals decreases from a dense sphere surrounding the ants inside the nest to only a narrow trail leading away from the nest. As a result, callows attempting to leave the nest would experience a sudden decrease in chemotactual stimulation, with the result that they would become disoriented. This, in turn, 
would cause the callows to reverse their direction of movement and return to the stimulus-saturated interior of the nest. By the end of the day's raid, and immediately preceding the start of an emigration, a large portion of the adult workers are out of the nest. Then, as the full-scale emigration progresses, the remaining adult population, together with the brood and queen, also leaves the nest. Thus, at some time between the beginning of an emigration and its peak, the relative concentration of chemical and tactual stimulation outside of the bivouac may be sufficient to attract the callows out of the nest. This may occur because the callows are particularly attracted to the chemical secretions and tactual stimuli that arise from one subpopulation of the entire colony (such as the adult workers, the brood, the queen, or even the booty). Or, the stimulative effect on the callows may be quantitative - that is the callows may leave the nest when the magnitude of stimulation outside the nest increases suffciently, regardless from which particular segment of the colony the stimuli arise.

We have recently made an observation in the field that is consistent with the hypothesis that high concentrations of social stimulation arising inside the nest serve to keep callow army ants inside the nest during the first few days of the nomadic phase. During a recent study of the nocturnal army ant species Neivamyrmex nigrescens (Cresson) in southeastern Arizona, we located a statary colony bivouacked beneath a rock in the bank of a creek. The statary raids were unusually weak, with only several dozen workers participating. On subsequent nights, the raids never increased in strength. One night we were surprised to find several dozen newly eclosed callow ants running sluggishly over the entire raiding route (which extended up to $50 \mathrm{~m}$ from the nest). No emigration occurred that night. The next night the callows were again observed along with the adults on the raiding trails. No emigration occurred the second night either. We then proceeded to dig up the nest, and we found that the entire colony consisted of between 100 and 200 mature adults and approximately 50 callows. There was no large mature adult or callow population, no brood, and no queen. As far as I know, this is the first report of callow army ants participating in raiding immediately after their eclosion from the pupal stage, and it is significant that in this one case there was no colony to speak of, and hence no large source of social stimulation.

In the army ants, as in social species representing many levels of invertebrate and vertebrate evolutionary history, immature individuals are not immediately integrated into the society of their group, 


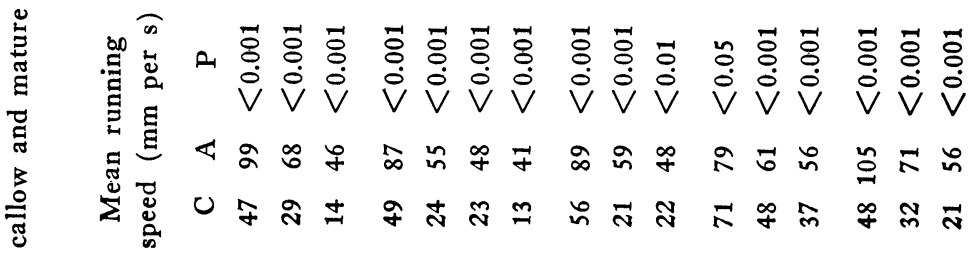

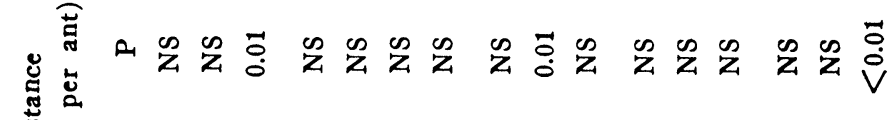

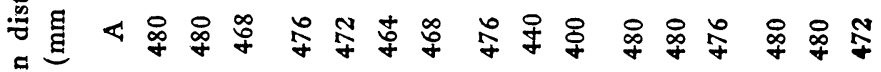

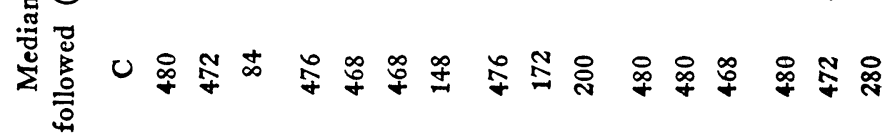

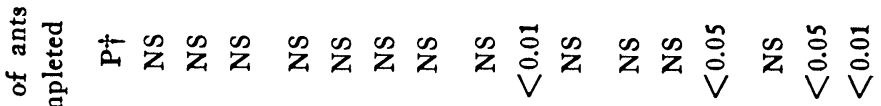
倇 U 0 -

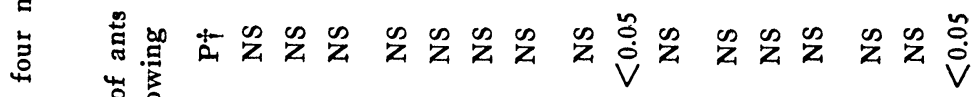
.

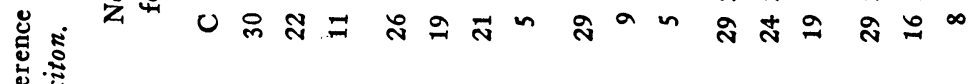

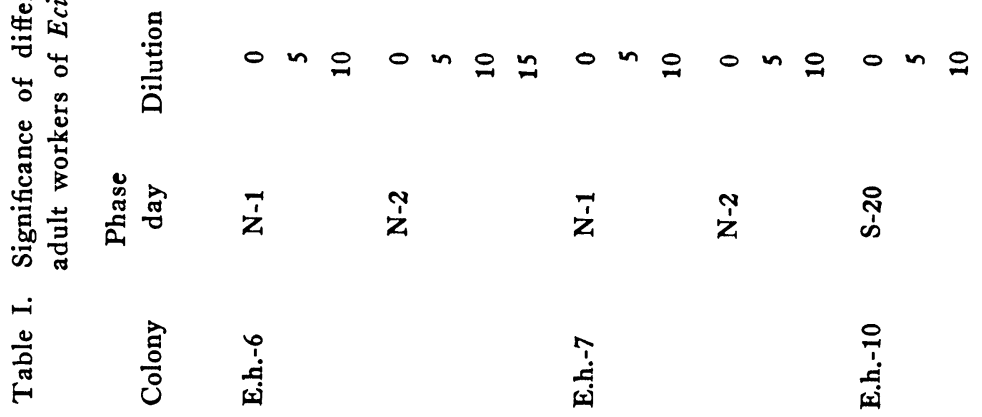


命

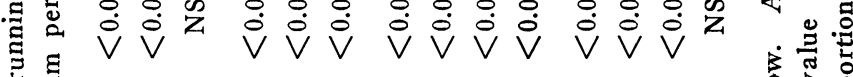

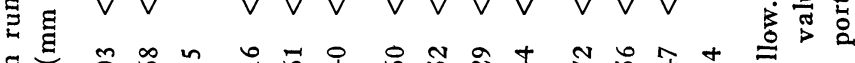

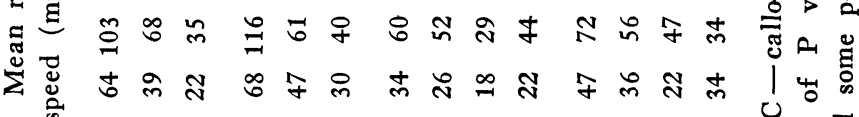

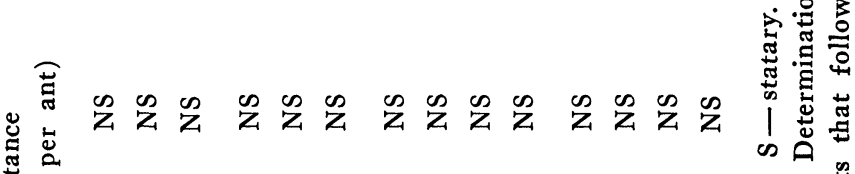
苞悬 范 范

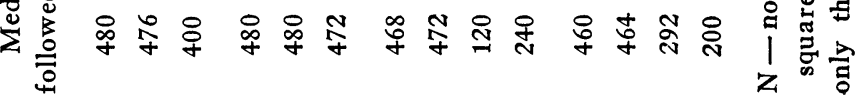

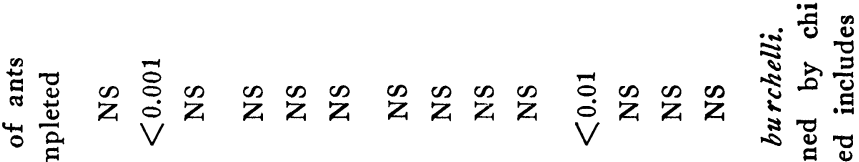

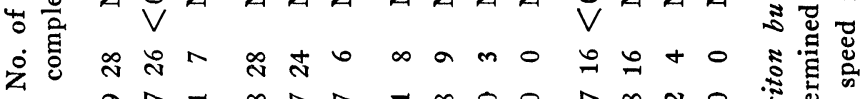

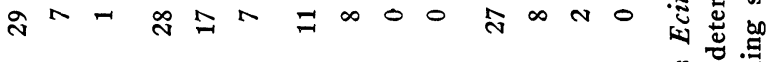

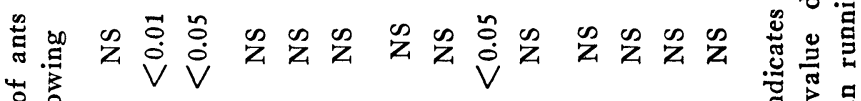

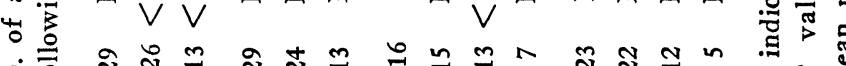
ட்

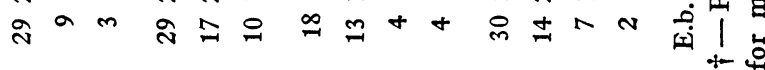

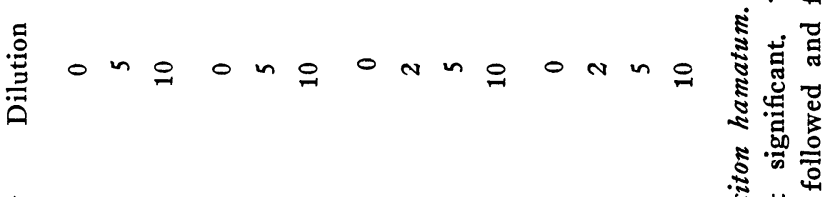

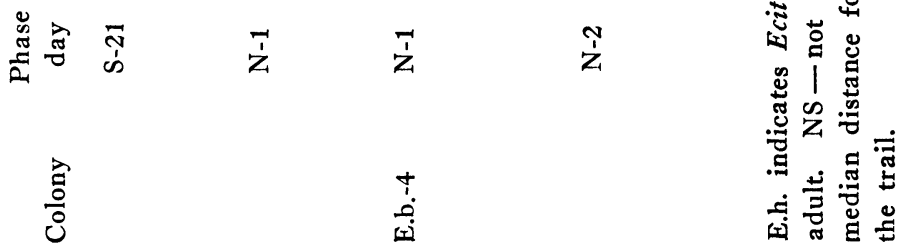


but become so gradually, as a result of numerous maturational and experiential effects that occur within the colony environment. Although the literature on the social behavior of ants is vast, especially studies concerning the pheromonal basis of sociality, behaviorists have largely ignored the developmental aspects of such studies. We hope that our contributions will stimulate more research on the development of social behavior in these insects.

\section{Acknowledgements}

This work was supported by a grant (GB-I4724) from the National Science Foundation and by a grant (\# I375) from the Research Foundation of the City University of New York.

\section{Summary}

Comparisons were made between the trail-following performance of callow and mature adult ants representing two species of the neotropical genus Eciton. The behavioral immaturity of the callows was evidenced by the fact that their running speeds over the trails were significantly slower than those of the older ants. Nevertheless, the number of callows able to follow along any portion of the trail, as well as the number able to complete the trail, was not significantly different from the older ants. Accordingly, we can not account for the absence of callow ants from raiding columns during the first few days after their emergence from the pupal stage of development as due to their inability to follow the chemical trail. We hypothesize that the callows' sensitivity to chemical and tactual stimulation inside of the nest may serve to prevent them from participating in raiding activities.

RetTenmeYer, C. W.

\section{Literature Cited}

1963. Behavioral studies of army ants. Univ. Kansas Sci. Bull., 44: 281-465.

SchNeIRLA, T. C.

1938. A theory of army-ant behavior based upon the analysis of activities in a representative species. Jour. Comp. Psychol., 25 : 51-90.

1952. Basic correlations and coordinations in insect societies with special reference to ants. Colloq. Internatl. Cent. Nat. Rech. Sci., 34: 247-269.

1971. Army Ants: A Study in Social Organization. (W. H. Freeman \& Co., San Francisco). 

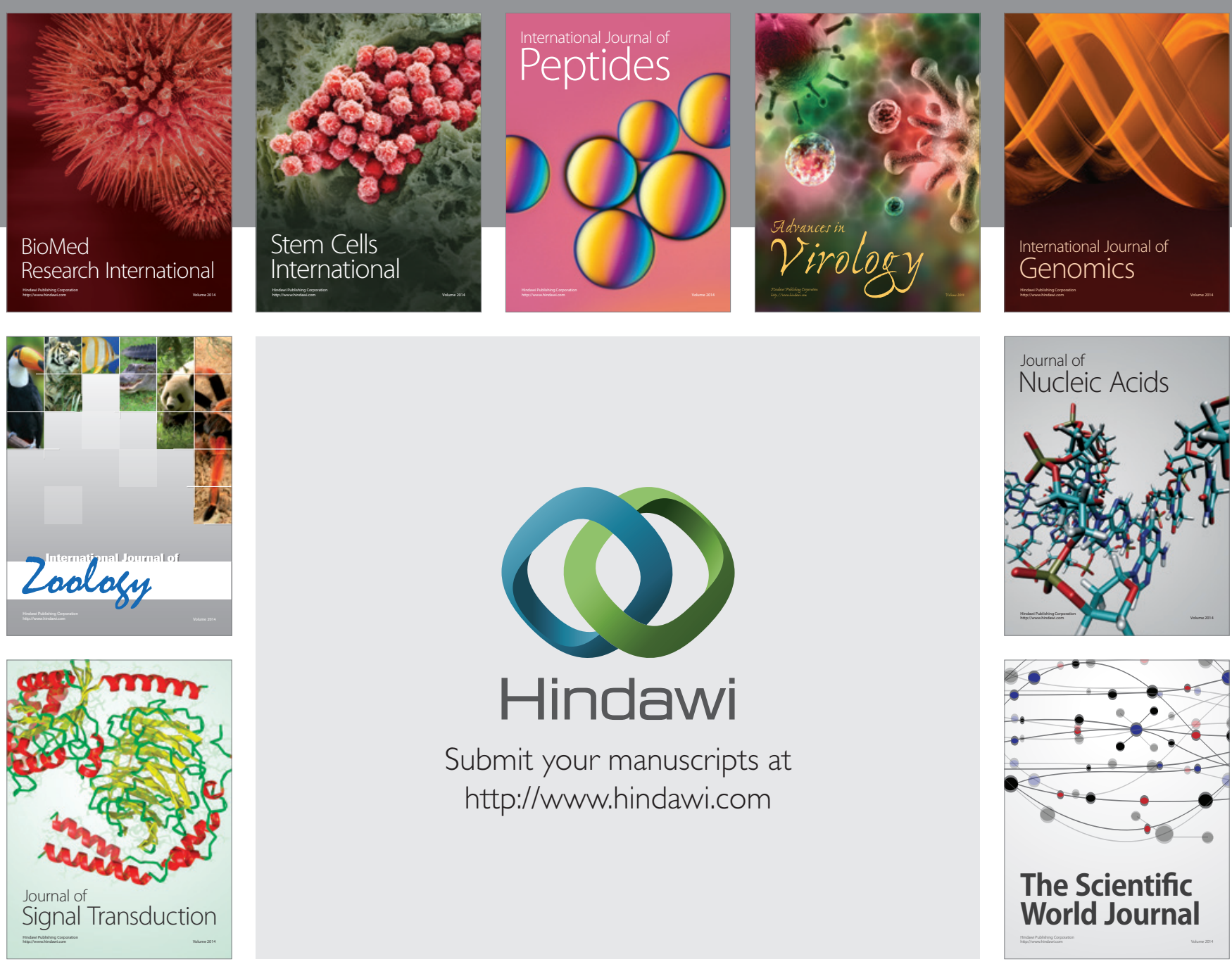

Submit your manuscripts at

http://www.hindawi.com
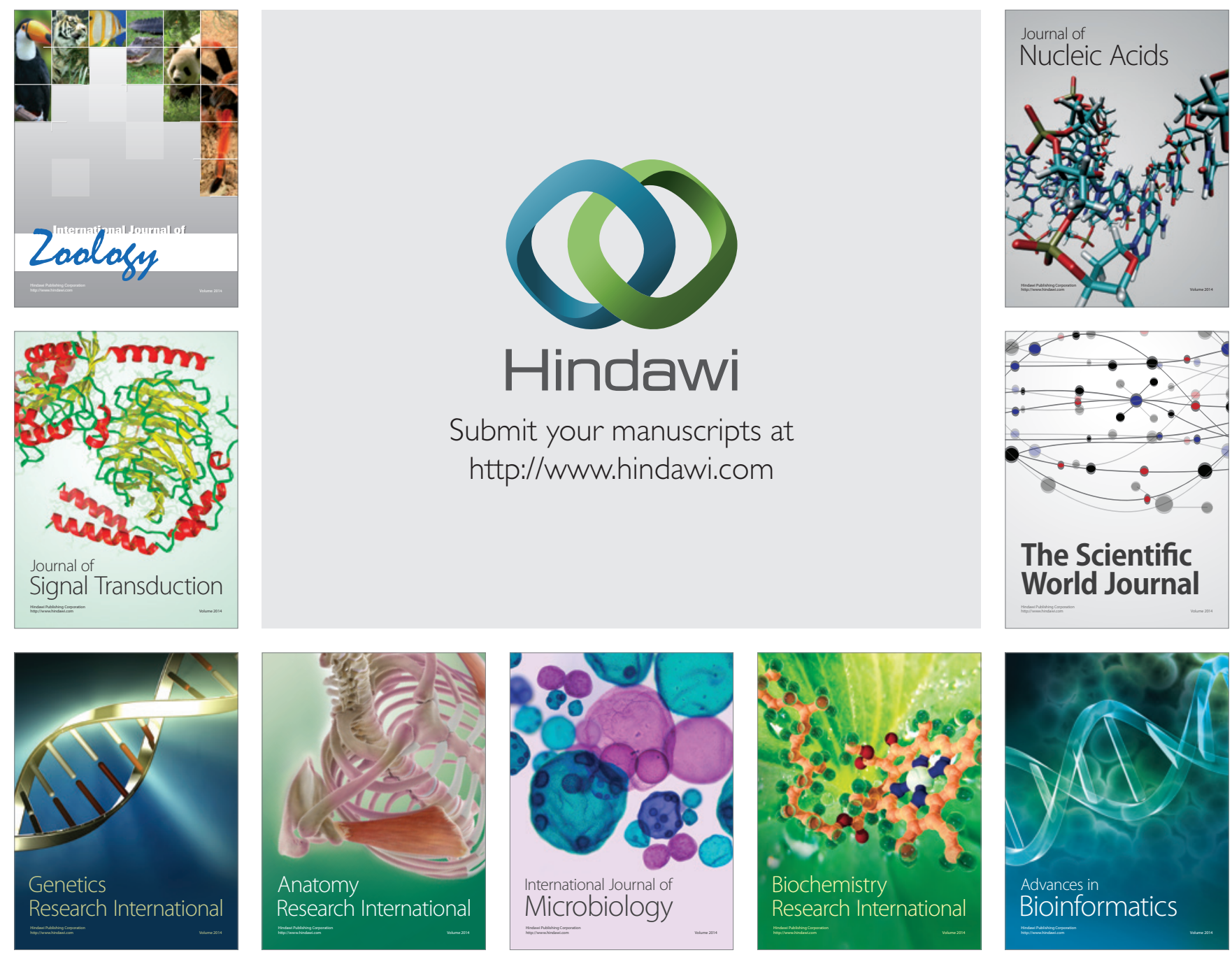

The Scientific World Journal
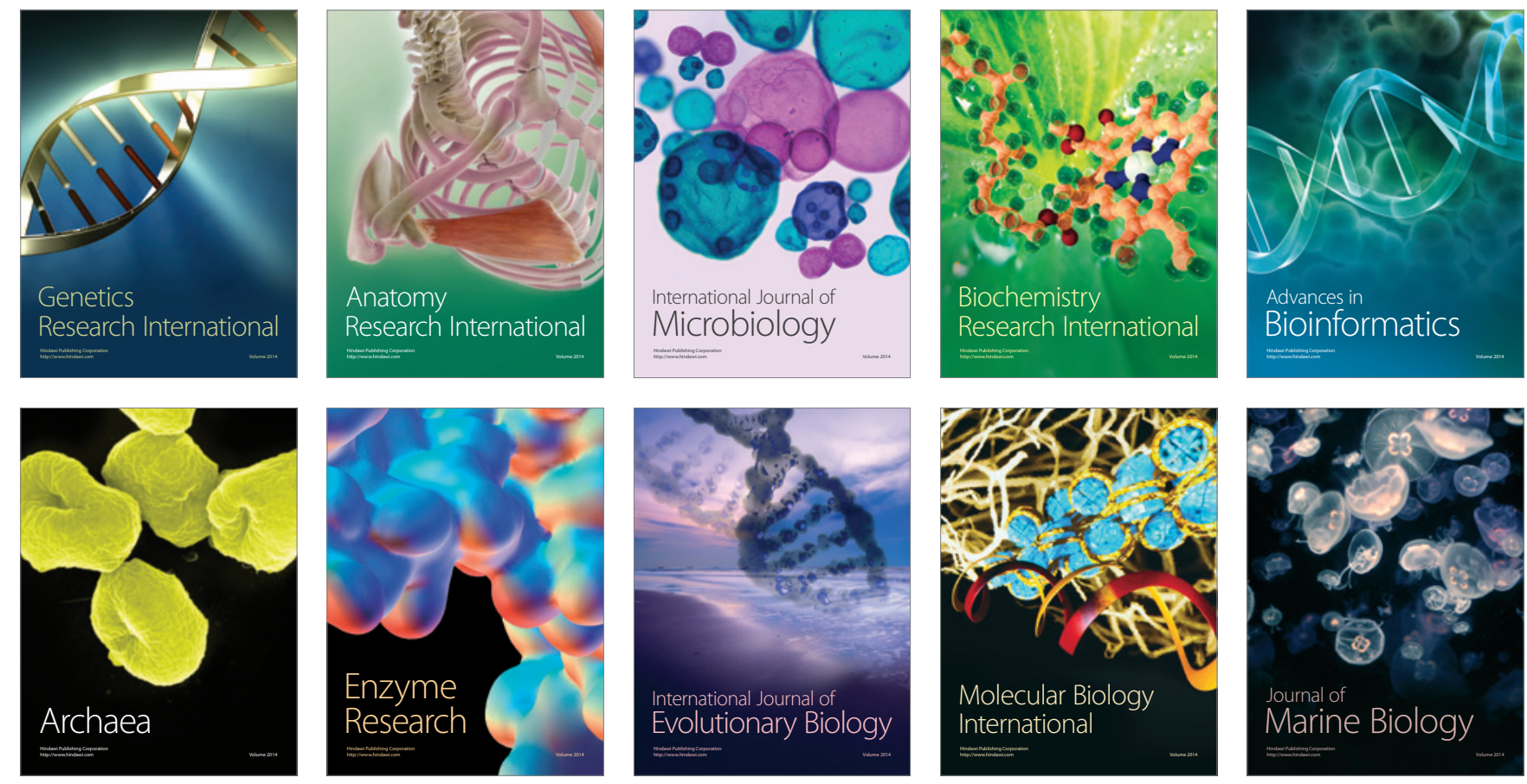